\title{
Experimental Investigation on Rock Filled Self-Compacting Concrete
}

\author{
Esakkiraj. P \\ Department of Civil Engineering \\ Sri Krishna College of Technology \\ Coimbatore, Tamilnadu \\ Maruthamuthu. $\mathrm{P}$ \\ Department of Civil Engineering \\ Sri Krishna College of Technology \\ Coimbatore, Tamilnadu
}

\author{
Ezhilarasan. G \\ Department of Civil Engineering \\ Sri Krishna College of Technology \\ Coimbatore, Tamilnadu \\ Barath Kumar. V \\ Department of Civil Engineering \\ Sri Krishna College of Technology \\ Coimbatore, Tamilnadu
}

\begin{abstract}
This project presents the experimental study on Self Compacting Concrete (SCC) with partial filling of Rock Gravel. This study investigated two of the two of the most controversial issues regarding Rock Filled Concrete (RFC)-the filling performance of SCC and the large interface between SCC and rocks. These issues were examined through an experimental setup designed to stimulate SCC flow in rock skeleton. The main objective is to be determine the compressive strength and split tensile strength on Rock filled self compacting concrete. The work involves several SCCs mixes. For each mix preparation Ten cube specimens and Five cylinder specimens are cast and cured. The specimens are cured in water for 7 and 28 days. The slump cone, L-BOX, J-RING, and V-FUNNEL test are carried out on the fresh Self Compacting Concrete with the help of guidelines EFNARC-2002.
\end{abstract}

The Hardened concrete properties such as compressive strength, Split Tensile Strength are determined. The result show that SCC with Rock filled concrete and super plasticizers is mixed with optimum SCC. After each mix proportion, specimens are casted and cured for 28 days in water and compressive strength and split tensile values are determined

Keyword-SCC;RFC;EFNARC;M-Sand; Compresion;Split.

\section{INTRODUCTION}

Self Compacting concrete is a new kind of high performance concrete with excellent deformability and segregation resistance, was first developed in Japan in 1986. It is a special kind of concrete that can flow through and fill the gaps of reinforcement and corners of molds without any need for vibration and compaction during the placing process.

The application of concrete without vibration in construction in not new. For examples, placement of seal concrete underwater is done by the use of a tremie without vibration, mass concrete has been placed without vibration. These seal, mass and shaft concrete are generally of lower strength, less than $34.5 \mathrm{Mpa}$ and difficult to attain consistent quality. To achieve this mineral admixtures such as fly ash and chemical admixtures like super plasticizer, viscosity modifying agent are used in mix design of the concrete.

The performance required for concrete structure is more complicated and diversified. The concrete is required to have properties like high fluidity, high strength, high durability, better serviceability and long service life of concrete structures. In order to address these requirement self compacting concrete was developed.

Rock-filled concrete was first developed in China as an application of SCC in massive concrete construction, with lower cost and heat of hydration. Since then, various investigations have been carried out, showing that this type of concrete performs satisfactorily with regard to strength, permeability and other properties. It has been used in practical structures mostly as the mass concrete in China since Aug 2005 with the benefits of its low heat of hydration, short construction period as well as the low cost and environmental friendly.

Process of RFC construction was proposed by Jin,F. et al. (2005) and An, X. et al. (2005). First, fill the working space with large-scale rock blocks with a size of more than 30 $\mathrm{cm}$ to form a rock-block mass. Then, pump or pour SCC on the surface of rock-block mass directly. Thereafter, RFC will be formed since SCC can fill the space between rock blocks by its good fluidity and high segregation resistance. And it should be noticed that the thickness of rock-block mass is pro- posed less than $1.5 \mathrm{~m}$ to ensure the filling effect of SCC.

Since the development of RFC in 2003, the concrete has already been used in two hydraulic engineering projects and is planned to be used in a few more projects. The main reasons for the employment of RFC can be summarised as:

- Using low unit cement content in the composite material results in low heat of hydration, which makes it much easier to ensure temperature control;

- Simplifying the placement of RFC by allowing for the use of general purpose machinery, eliminating the surface roughening process and also allowing for continuous pouring of SCC, all contribute to faster construction activities and shortening of the overall construction period;

- Eliminating the need to vibrate concrete by using SCC results in compaction being ensured independent of the quality of construction work.

- Using the rock-block mass as the skeleton of concrete results in relatively little drying and shrinkage;After conducting the flow characteristic experiments the concrete mix was poured in the moulds required for the strength assessment. After pouringthe concrete in the moulds, no compaction was given either through vibrated or through hand 
compaction. Even the concrete did not require any finishing operation. After 24 hours of casting, the specimens were demoulded \& were transferred to the curing tank. Wherein they were allowed to cure for 28 days.

\section{LITERATURE REVIEW}

Yuetao xie, David et al.,(2014) This study investigated two of the most controversial issues regarding RFC the filling performance of SCC and the large interface between SCC and rocks. The findings indicates that the interface microstructure of RFC greatly depends on the filling performance of SCC which is significantly affected by the size and condition of large rocks. The experimental results show that filling performance of SCC largely depend on size and condition of aggregates although the yield stress of SCC also affect filling capacity.

Yuehei An et al., (2009) Preparation of rock blocks Rubble and cobble stone with a size not less than $30 \mathrm{~cm}$ are all permitted to use as blocks of rock during the RFC construction. The experimental results shows Clean working space and rock blocks Before RFC construction, the working space and rock blocks should be cleaned first, and the requirements of conventional concrete dam construction need to be satisfied. It has been employed in a number of hydraulic engineering structures already, in china. Besides, cost and environment impact assesments of RFC construction system. Flocculation of cement particles occur in a concrete mix without superplasticizer which reduces the workability of concrete, however for the same water-cement ratio there is a uniform distribution of cement particles for a concrete mix with superplasticizer. All of these studies and applications showed that RFC had great advantages in massive concrete structures.

Dinesh.A , Harini.S et al (2004) This study deals with the self-compacting concrete where the cement is partially replaced with fly ash and silica fume and it is observed that increase in workability and compressive strength. Another advantage of SCC is that the time required to place large sections is considerably reduced.In experimental results that the compressive strength decreases with the increase in percentage of fly ash and increases with increase in percentage of silica fume.It flows easily at suitable speed into formwork without blocking through the reinforcement without being heavily vibrated.

P.Kannan,C.F.Jerin et al.,(2008) This studied that at this paper mainly focuses on the mix proportions by partial replacement of cement and fine aggregate by various eco friendly materials and to critically review the mechanical properties of the SCC. It was observed that the fine materials improve the properties of SCC at low water binder ratio and addition of super plasticizers. The result shows that SCC with mineral admixtures shows satisfactory results. The research focus on viscosity agent and the interaction with super plasticizer is worthwhile in self compacting concrete. Muhammed Shahzad Baig et al., (2016) Studied at distinctive concrete which flows and consolidates under its own weight is distinguished as self compacting concrete. various experimental efforts have been carried out to check the effects of limited replacement of cement or aggregate on properties of self compacting concrete. This paper includes review of various studies conducted on use of different admixtures / materials on strength of self compacting concrete. Reinforcement bars with a nominal diameter of $15 \mathrm{~mm}$ are installed at the gate with centre to centre distance of $50 \mathrm{~mm}$. This creates a clear spacing of $35 \mathrm{~mm}$ between the bars. The left hand section is filled with about 20 kilograms of concrete. The gate is then lifted and the concrete flows to the other section. The results shows that SCC with mineral admixture/ waste materials exhibited acceptable and satisfactory results and verified by different tests.

Eng Jin Hu et al.,(2016) Studied that at first, a brief introduction to RFC dams is presented in this paper. Then, some Researches of RFC are introduced. The research focus on mechanical properties and thermal-physical properties of RFC. Some data in situ are also presented. Research results demonstrated that the RFC has good properties to be employed to build dams. The results shows that the after hardening properties of RFC are similar to those of mass concrete, much better than those of masonry. RFC not only has the good performance of SCC such as self-compaction without vibration, but also reduces the heat of hydration.

Qioung wu et al.,(2013) RFC is produced by filling the voids of rock blocks with SCC, which has good fluidity and segregation resistance. To guarantee the required workability of SCC, a mix design method for SCC based on its paste rheological characteristics was developed. The proposed method yielded practical benefits by saving on the amount of laboratory work, testing time, and raw materials. The dispersion of cement particles occur due to steric hindrance. Steric hindrance depends on the length of main chain, length and number of side chain. However, they are more sensitive to overdosing, and can lead to problems such as retardation and excessive air entrainment .The integrated performance of RFC was studied by conducting tests on its compaction, compression strength, tensile strength, and permeability.

\section{MATERIALS USED}

\section{A. $\quad$ Fine Aggregate $=M$-sand \\ B. Coarse Aggregate \\ - $12.5 \mathrm{~mm}$ gravel \\ - $5 \mathrm{~cm}$ rock gravel}

C. Cement

OPC grade-53

D. Superplasticizers

GLENIUM C-303

\section{MEDHODS}

\section{A. Rock Gravel}

Process of RFC involves two major steps:

[i].Filling in-situ formwork with large-scale rocks (grain size $>30 \mathrm{~cm}$ ).

[ii].Pouring fresh SCC into pre-packed rock skeleton to fill the voids between rocks.

Manufactured sand (M-Sand) is a substitute of river sand for concrete construction.Manufactured sand is produced 
from hard granite stone by crushing. The crushed sand is of cubical shape with grounded edges, washed and graded to as a construction material. The size of manufactured sand (MSand) is less than $4.75 \mathrm{~mm}$. Manufactured sand is an alternative for river sand. Due to fast growing construction industry, the demand for sand has increased tremendously, causing deficiency of suitable river sand in most part of the world. Due to the depletion of good quality river sand for the use of construction, the use of manufactured sand has been increased. Another reason for use of M-Sand is its availability and transportation cost.

In the case of SCC, rounded aggregates would provide a better flowability and less blocking potential for a given water-to-powder ratio, compared to angular and semi-rounded aggregates. Moreover, the presence of flaky and elongated particles may give rise to blocking problems in confined areas, and also increase the minimum yield stress. The maximum aggregate size varying from 10 to $20 \mathrm{~mm}$.Incorporation of aggregate shape in the mixture design would enable the selection of appropriate paste content required to overcome these difficulties. It is possible that the highly flowable nature of SCC could allow a higher proportion of flaky aggregates compared to normal concrete. However, this aspect needs to be checked.

\section{B. Superplasticizers,}

It also known as high range water reducers(HRWR), are chemical admixtures used where well-dispersed particle suspension is required. It is a essential component of SCC. GLENIUM C-303 is used because it is essential component of SCC to provide workability.

Ordinary Portland water normally of $\mathrm{pH} 7$ is used for mixing \& curing the concrete specimen.

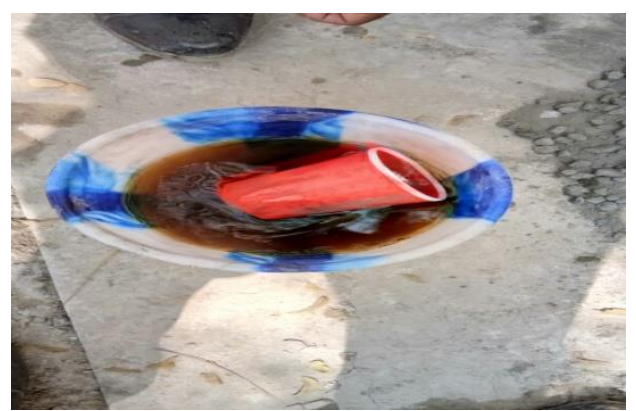

Fig 1Glenium C-303

\section{EXPERIMENTAL PROCEDURE}

The cement, sand and coarse aggregates were weighted according to the mix proportion of $1: 1.8: 1.7$. In order to study the effect on fresh concrete properties in SCC the rock gravel is added in concrete at bed level. To this dry mix the required quantity of water was added and thoroughly mixed. To this the super plasticizers was added at the rate of $1.5 \mathrm{lit} / \mathrm{m}^{3}$ of cementitious material and mixed immediately. The entire mix was thoroughly mixed once again. At this stage, almost the concrete was in a flowable state.

Now, the flow characteristic experiments for selfcompacting concrete like slump flow test, V-funnel test,
L-box test, \& U box test were conducted. In terms of slump flow, all SCC exhibited satisfactory slump flows in range of $550-800 \mathrm{~mm}$, which is an indication of a good deformability.

After conducting the flow characteristic experiments the concrete mix was poured in the moulds required for the strength assessment. After pouring the concrete in the moulds, no compaction was given either through vibrated or through hand compaction.

Even the concrete did not require any finishing operation. After 24 hours of casting, the specimens were demoulded \& were transferred to the curing tank. Wherein they were allowed to cure for 28 days.

For compressive assessment, cubes of size $150 \mathrm{~mm}$ $\mathrm{x} 150 \mathrm{~mm} \times 150 \mathrm{~mm}$ were prepared. For tensile strength assessment, cylinders of diameter $150 \mathrm{~mm}$ \& length $300 \mathrm{~mm}$ were prepared. Indirect tension test ,was carried on these cylindrical specimens. After 28 days of curing the specimens were tested for their respectively strengths. The test results were studied and the optimum SCC were found.

Same procedure of mixing is repeated for the adding of rock gravel in bed level to optimum SCC mix. The $5 \mathrm{~cm}$ rock gravel was settled down in moulds at bed level. The entire mix was thoroughly mixed \& poured into the moulds without any compaction. After 28 days curing, the specimens were tested for their respectively strength and the optimum value of SCC has been found.

Self-compacting concrete is a high performance concrete that can be compacted into every corner of a formwork, purely by means of its own weight and without the need for vibrating compaction. This concrete is defined as follows at the three stages of concrete: Fresh: self-compactable; Early age: avoidance of initial defects; After hardening: protection against external factors.

The addition of super plasticizers in the truck during transit is a fairly new development within the industry. Admixtures added in transit through automated slump management systems, allows concrete producers to maintain slump until discharge without reducing concrete quality. I Summarized here that the addition of super plasticizers in SCC and improves the mechanical properties mainly the tensile and compressive strength of self compacting concrete (SCC).

\section{A. Fresh Properties Of Scc}

The main properties of SCC in plastic state are :

1. Filling ability (Slump-flow, V-funnel).

2. Passing ability ( J-ring, L-box )

3. High resistance to segregation ( V-funnel at T5 minutes )

\section{Filling Ability of Self Compacting Concrete}

It is the ability of SCC to flow into all spaces within the formwork under its own weight. Tests, such as slump flow, V-funnel etc, are used to determine the filling ability of fresh concrete.

\section{Passing Ability of Self Compacting Concrete}

It is the ability of SCC to flow through tight openings, such as spaces between steel reinforcing bars, under its own 
weight. Passing ability can be determined by using U-box, Lbox, Fill-box, and J-ring test methods.

\section{Segregation Resistance}

The self compacting concrete must meet the filling ability and passing ability with uniform composition throughout the process of transport and placing.

\section{FRESH CONCRETE PROPERTIES}

\section{A. Flowability Tests:}

1. Slump flow test (1) and $\mathrm{T} 50 \mathrm{~cm}$ test (2)

a) Introduction

The slump flow is used to assess the horizontal free flow of SCC in the absence of obstructions. It was first developed in Japan (1) for use in assessment of underwater concrete. The test method is based on the test method for determining the slump. The diameter of the concrete circle is a measure for the filling ability of the concrete.

b) Assessment of test

This is a simple, rapid test procedure, though two people are needed if the $\mathrm{T}_{50}$ time is to be measured. It can be used on site, though the size of the base plate is somewhat unwieldy and level ground is essential. It is the most commonly used test, and gives a good assessment of filling ability. It gives no indication of the ability of the concrete to pass between reinforcement without blocking, but may give some indication of resistance to segregation. It can be argued that the completely free flow, unrestrained by any boundaries, is not representative of what happens in practice in concrete construction, but the test can be profitably be used to assess the consistency of supply of ready-mixed concrete to a site from load to load.

\section{B. J Ring test}

1. Introduction:

The principle of the JRing test may be Japanese, but no references are known. The JRing test itself has been developed at the University of Paisley. The test is used to determine the passing ability of the concrete. The equipment consists of a rectangular section $(30 \mathrm{~mm} \times 25 \mathrm{~mm})$ open steel ring, drilled vertically with holes to accept threaded sections of reinforcement bar. These sections of bar can be of different diameters and spaced at different intervals: in accordance with normal reinforcement considerations, $3 \mathrm{x}$ the maximum aggregate size might be appropriate. The diameter of the ring of vertical bars is $300 \mathrm{~mm}$, and the height $100 \mathrm{~mm}$.

\section{Assessment of test}

These combinations of tests are considered to have great potential, though there is no general view on exactly how results should be interpreted. There are a number of options - for instance it may be instructive to compare the slump-flow/JRing spread with the unrestricted slump-flow.

\section{C. $\quad V$ funnel test and $V$ funnel test at $T$ 5minutes}

1. Introduction

The test was developed in Japan and used by Ozawa et al. The equipment consists of a V-shaped funnel, shown in Fig.D.4.1. An alternative type of Vfunnel, the $\mathrm{O}$ funnel, with a circular section is also used in Japan.The described V-funnel test is used to determine the filling ability (flowability) of the concrete with a maximum aggregate size of $20 \mathrm{~mm}$. The funnel is filled with about 12 litre of concrete and the time taken for it to flow through the apparatus measured.After this the funnel can be refilled concrete and left for 5 minutes to settle. If the concrete shows segregation then the flow time will increase significantly.

2. Assessment of test

Though the test is designed to measure flowability, the result is affected by concrete properties other than flow. The inverted cone shape will cause any liability of the concrete to block to be reflected in the result - if, for example there is too much coarse aggregate. High flow time can also be associated with low deformability due to a high paste viscosity, and with high inter-particle friction. While the apparatus is simple, the effect of the angle of the funnel and the wall effect on the flow of concrete is not clear.

TABLE 1 Flowability Test Results

\begin{tabular}{|c|c|c|c|}
\hline S.NO & METHODS & RESULTS & UNITS \\
\hline 1. & Slump flow & 686 & $\mathrm{~mm}$ \\
\hline 2. & J ring apparatus & 7.4 & $\mathrm{~mm}$ \\
\hline 3. & V funnel & 4 & $\mathrm{Sec}$ \\
\hline 4. & V funnel at T5min & 3 & $\mathrm{Sec}$ \\
\hline 5. & L box $\left(\mathrm{h}_{2} / \mathrm{h}_{1}\right)$ & 0.93 & $\mathrm{~mm}$ \\
\hline
\end{tabular}

\section{MIX DESIGN}

The mix design of self-compacting concrete is a trial and error method. Many references available for mix proportioning of SCC. Here we use mix proportioning based on previous investigation strength data using Japanese method and also based on EFNARC-2002 guidelines. In the Japanese method coarse and fine aggregate contents are initially fixed so that self compactability is achieved by adjusting the water/powder ratio and super plasticizer dosage. Strength requirements are assessed from field trails of SCC at a later stage. In our investigation we incorporate the procedures of EFNARC-2002 guidelines. These guidelines gives the range for coarse aggregate and fine aggregate content and based on the limit the approximate mix design for M40 grade of concrete is obtained.

\section{A. Mix Design Ratio}

Ratio Of Mix Design is 1: 1.8: 1.7

TABLE 2 Scc Mix ratio

\begin{tabular}{|c|c|}
\hline Cement $\left(\mathrm{kg} \backslash \mathrm{m}^{3}\right)$ & 459 \\
\hline Fine aggregate $\left(\mathrm{kg} \backslash \mathrm{m}^{3}\right)$ & 823 \\
\hline Coarse aggregate $\left.\left(\mathrm{kg}^{3}\right)^{3}\right)$ & 810 \\
\hline Water $\left(\mathbf{k g} \backslash \mathrm{m}^{3}\right)$ & 146 \\
\hline Fibers $\left(\mathrm{kg} \backslash \mathrm{m}^{3}\right)$ & 0.0 \\
\hline Super plasticizer $(\mathrm{ml})$ & 45.9 \\
\hline
\end{tabular}




\section{HARDENED CONCRETE TEST}

\section{A. Compressive Strength Test}

Compressive strength test results are primarily used to determine that the concrete mixture as delivered meets the requirements of the specified strength, in the job specification. Strength test results from cast cylinders may be used for quality control, acceptance of concrete, or for estimating the concrete strength in a structure for the purpose of scheduling construction operations such as form removal or for evaluating the adequacy of curing and protection afforded to the structure. Cylinders tested for acceptance and quality control are made and cured in accordance with procedures described for standard-cured specimens in ASTM C 31 Standard Practice for Making and Curing Concrete Test Specimens in the Field. For estimating the in-place concrete strength, ASTM C 31 provides procedures for field-cured specimens. Cylindrical specimens are tested in accordance with ASTM C 39.

\begin{tabular}{|c|c|c|}
\multicolumn{2}{|c|}{ TABLE 3 Compressiom test results } \\
\hline Specimen & $\mathbf{7}$ days $\left(\mathbf{N} / \mathbf{m m}^{2}\right)$ & $\mathbf{2 8}$ days $\left(\mathbf{N} / \mathbf{m m}^{2}\right)$ \\
\hline $\begin{array}{c}\text { M40 mix Without } \\
\text { rock filled }\end{array}$ & 27.8 & 41 \\
\hline M40 mix With rock filled 4cm & 28.3 & 41. \\
& & 9 \\
\hline M40 mix With rock filled 5cm & 28.5 & 42. \\
& & 5 \\
\hline M40 mix With rock filled & 29.3 & 43. \\
6cm & & 2 \\
\hline
\end{tabular}

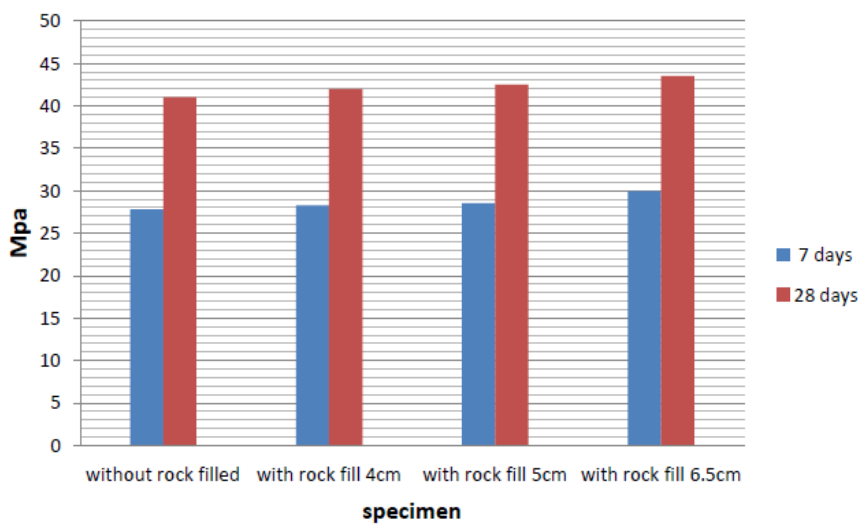

Fig 2 Bar chart showing compression test results

\section{B. Split Tensile Strength Test}

This test method is used for the determination of splitting tensile strength of cylindrical concrete specimen. Splitting tensile strength is helpful for the following purposes;

Splitting tensile strength is generally greater than the direct tensile strength and lower than the flexural strength (modulus of rupture).

Splitting tensile strength is used in the design of structural light weight concrete members to evaluate the shear resistance provided by concrete and to determine the development length of the reinforcement.

$$
\mathrm{T}=2 \mathrm{P} /(\mathrm{ld})
$$

This test method consists of applying a diametrical force along the length of a cylindrical concrete at a rate that is within a prescribed range until failure. This loading induces tensile stresses on the plane containing the applied load and relatively high compressive stresses in the area immediately around the applied load. Although we are applying a compressive load but due to Poisson's effect, tension is produced and the specimen fails in tension. The maximum load sustained by the specimen is divided by appropriate geometrical factors to obtain the splitting tensile strength. Same procedure of mixing is repeated for the adding of rock gravel in bed level to optimum SCC mix. The $5 \mathrm{~cm}$ rock gravel was settled down in moulds at bed level.

\begin{tabular}{|c|c|}
\hline \multicolumn{2}{|c|}{ TABLE 4 Split tensile test results } \\
\hline Specimen & $\begin{array}{c}\mathbf{2 8} \text { days } \\
\left(\mathbf{N} / \mathbf{m m}^{2}\right)\end{array}$ \\
\hline $\begin{array}{c}\text { M40 mix } \\
\text { (Without Rock fill) }\end{array}$ & 3.56 \\
\hline $\begin{array}{c}\text { M40 mix } \\
\text { (Rock filled 4cm) }\end{array}$ & 3.90 \\
\hline $\begin{array}{c}\text { M40 mix } \\
\text { (Rock filled 5cm) }\end{array}$ & 4.25 \\
\hline $\begin{array}{c}\text { M40 mix } \\
\text { (Rock filled 6.5cm) }\end{array}$ & 4.95 \\
\hline
\end{tabular}

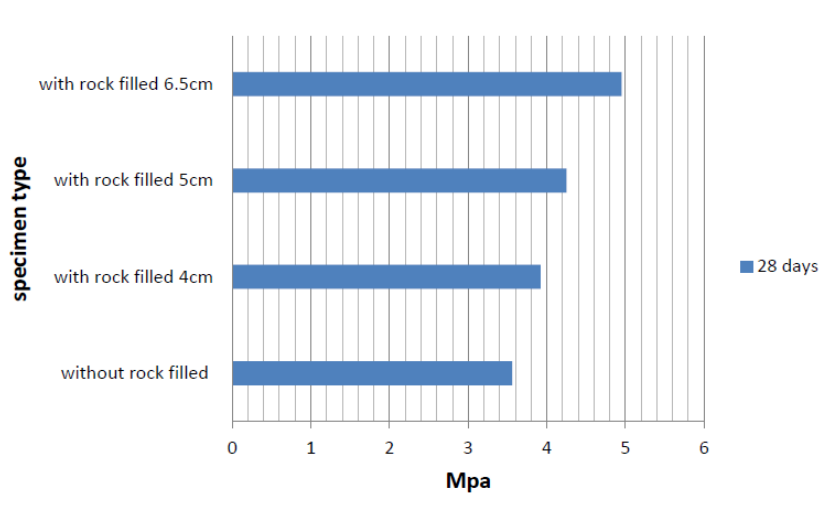

Fig 3 Bar chart showing split tensile test results

\section{CONCLUSIONS}

As a new kind of concrete, RFC performs satisfactorily in the early age and after hardening, which could satisfy the requirement of hydraulic engineering project, especially in the massive concrete construction because of its simple execution, low heat of hydration, low cost, and so on of RFC, such as drying and hardening shrinkage and freezethaw resistance. In addition, establish an efficient construction system of RFC.

- As no specific mix design procedures for SCC are available, the mix design can be done with the conventional absolute volume method, and suitable adjustments can be done as per the guidelines provided by different agencies, especially by EFNARC 2002.

- It has been verified, by using the slump flow, L-box test and other tests on fresh SCC that selfcompacting concrete (SCC) achieved consistency and self-compactability under its own weight, without any external vibration or compaction.

- It can be concluded that method of curing has considerable effect on the mechanical properties including compressive, split tensile strength of Rock 
filled SCC. The strengths are found better for Rock filled self compacting concrete.

- Immersion curing seems to be best method for curing in Rock filled concrete as well.

\section{REFERENCES}

[1] Yuetao xie, David j.corr and Mohend chaouche., "Filling capacity of self compacting concrete and its influence on the rock-filled concrete" cement and concrete research, Vol 56(2014) 121-128.

[2] Yuehei An , Miasong Huang, Hu Zhou and Feng Jin., "The Rockfilled concrete in China-self compacting concrete for massive concrete", International symposium on of SCC, china june 5-7,2009.

[3] Dinesh.A , Harini.S , Jasmine Jeba.P and Shagufta Javed, "Experimetal study on self Compacting concrete", IJESRT Vol ISSN :2277-9655

[4] P.Kannan,C.F.Jerin, Dr.K.Murali, "A review on self compacting concrete", IJAREM Vol 2,8-12

[5] Muhammed Shahzad Baig, Dr.Muhammed Maqbool Sadiq, "Influence of mineral admixtures on of SCC", IJIERE, vol-3,issue 4 2016

[6] Eng Jin , Hu Zhou, Xuehui AN., "Research on rock filled concrete dam", LTBD 2017,Vol-2,56-62

[7] Qioung wu, Miansong huang,Hu zhou .,2013, "Rock-filled concrete, the new form of SCC in hydraulic engineering in China", Elsevier Vol 54-99.

[8] S.Ozkuzukiran, Y.Ozkan,G.Ozyazicioglu, S.Yildiz.,2013,"Settlement behaviour of a concrete faced Rock-fill dam". IJIERE Vol 24,16651678

[9] Evangeline.K, Dr.M.Neelamegam .,2014,"Effect of Superplasticizer on Workability and Mechanical Properties of Self-Compacting Concrete". IOSR journal pp 18-29.

[10] S.M.DUMNE., 2014,"Effect of Superplasticizer on Fresh and Hardened Properties of Self-Compacting Concrete". AJER Vol3,205-211. 